TPeriodica Polytechnica Civil Engineering

\author{
62(2), pp. 353-362, 2018 \\ https://doi.org/10.3311/PPci.11111 \\ Creative Commons Attribution (i)
}

RESEARCH ARTICLE

\section{Analyzing the Edge Cracked Semicircular Disc under Uniform Compressive (ECSD(UD)) Load}

\author{
Amirhoshang Akhaveissy ${ }^{1}$, Ali Permanoon ${ }^{* 1}$, Roya Raeisi ${ }^{3}$
}

Received 30 July 2016; Revised 13 February 2017; Accepted 22 February

\begin{abstract}
In this study, by employing the edge cracked semicircular disc under uniform $(E C S D(U C))$ and calculating the shape factor, the toughness of brittle materials under uniform compressive load has been quickly evaluated. Samples, on the loading location and the support, under angle $\beta$ changing from 0 to 10 degrees, with the crack length (a) changing from 1 to $29 \mathrm{~mm}$ and the thickness (t) changing from 1 to $30 \mathrm{~mm}$ were investigated. By taking into account the simultaneous effect of thickness and crack length, a relationship for the shape factor (F) of the ECSD(UC) was presented.
\end{abstract}

\section{Keywords}

Edge Cracked Semicircular Disc, photo-elastic material, stress intensity factor, shape factor, finite element

1 Department of Civil Engineering, Faculty of Engineering, Razi University, P.O. Box: 67149-67346, Kermanshah, Iran

* Corresponding author, e-mail : permanoon.ali@gmail.com

\section{Introduction}

One of the important parameters of fracture mechanics is stress intensity factor $(K)$. This shows the strength of the cracked sample against crack expansion. When a cracked specimen is subjected to external load, a high stress concentration around tip of the crack occurs. When this stress concentration at the tip of the crack reaches its critical limit, the specimen fractures and the corresponding stress intensity factor of this critical stress are called the plane strain fracture toughness $\left(K_{I C}\right)$ which is among the constant properties of materials. To calculate the stress intensity factor in experimental samples, the shape factor (F) should be obtained which is very important and depends on the geometry of the sample and the relative crack length. Few studies have been carried out on calculating the optimized shape factor $(\mathrm{F})$. Determining the toughness of materials requires advanced tensile-bending lab equipment and researchers have always tried to devise simple experiments to obtain the toughness of materials in the lab. Therefore, the main goals of this study are to obtain the stress intensity factor (SIF) of the edge cracked semicircular disc under uniform compressive load (ECSD(UC)) and to calculate the optimized shape factor. Given the importance of crack expansion in different materials, researchers have always been striving to calculate the toughness and stress concentration at the tip of the crack. Westergaard [1] proposed imaginary equations for analyzing and calculating stress at the tip of the crack under different failure modes. Wang and Xing [2], using the Brazilian disc, studied the toughness of brittle materials such as stone under the first mode of failure $\left(K_{I}\right)$. Ayatollahi et al [3] studied the toughness of the second mode $\left(K_{I I}\right)$ of brittle material by performing the three-point bending test on the cracked semicircular disc. Lim et al [4] to evaluate the toughness of soft rock under a mixed-modes fracture conducted the threepoint bending test on the cracked semicircular disc. Surendra and Simha [5] presented a new experimental sample to determine the toughness of the first mode of brittle materials such as stone, glass, and ceramic under compressive load. Atkinson et al [6] investigated different modes of experimental samples and by compromising the results with the numerical results of 
the finite element method, proposed a relationship for the stress intensity factor under mixed modes fracture. Akbardoost et al [7], using the finite element method, calculated the variables of the crack tip including $K_{I}, K_{I I}$ and the constant coefficients of the third terms in Williams series expansion(A3,B3) for the holed-cracked flattened Brazilian disk (HCFBD) under a wide range of mixed-modes I,II. Aliha and Ayatollahi [8] assessed the toughness of brittle material, such as stone, using the cracked chevron notched Brazilian disc (CCNBD) under the combination of the first and the second failure modes. Also, based on the experimental results, they proposed an equation to calculate the toughness of the first and the second modes. Ayatollahi and Zakeri [9] improved the definitions of the first and second failure modes by taking into account T-Stress. Wei et al [10] investigated the failure toughness of the first mode of stone using the semicircular three-point bending disc (SCB). Gludovatz et al [11] investigated the effects of cooling speed and processing environment of melted metal on the failure toughness of metallic glass. Noury and Eriksson [12] investigated the cracked roller supports underneath bridges subjected to compression using a 2D finite element model. Zhu and Joyce [13] provided a thorough review on methods for testing toughness and design of samples, geometric properties, and standardizing the parameters and the properties of the tested materials. Dong [14] studied the effect of relative crack length and loading angle error on the Brazilian disc under combined failure modes. Using the finite element method, Dong et al [15] assessed the dynamic toughness of brittle materials by employing the Brazilian disc model. Maigre and Rittel [16] probed the dynamic toughness of materials subjected to compressive load under combined failure modes and the use of finite element method. Bui et al [17] proposed an exact theoretical method for calculating the dynamic stress intensity factor. Albinmousa [18] presented the shape factor of the edge notched tension specimen with limited width and under combined first and second failure modes. Keles and Tutluoglu [19] provided the equation of the shape factor of the first mode of the flattened Brazilian disc under compressive load. In addition to the abovementioned studies, the toughness of materials under fatigue loads was also investigated [20-23].

Despite extensive experience and numerous specimens for determining the toughness of materials, there is always the need for newer designs. In this study, the toughness of brittle materials is determined by subjecting edge cracked semicircular disc to uniform compressive load (ECSD(UC)). The goal is to propose an equation for the stress intensity factor based on the shape of the sample. Thus, by altering the length of the crack and the thickness of the sample, an equation for calculating the shape factor of the $\operatorname{ECSD}(\mathrm{UC})$ is presented. Compressive disc samples can be widely used in determining the stress intensity factors of brittle materials like ceramics, stone, and glass.

\section{Mechanical and Geometric Properties of the Samples}

The Photo-Elastic samples were made of Perspex epoxy resin material which have the Young's modulus $(E)$, the Poisson's ratio $(v)$ and a fringe constant $\left(f_{\sigma}\right)$ of $3000 \mathrm{MPa}, 0.33$, and $11772 \mathrm{Pam} /$ fringe, respectively. The thickness of the samples, the radius of the disc, and the load applied to all the samples are $6 \mathrm{~mm}, 30 \mathrm{~mm}$, and $395 \mathrm{~N}$, respectively. The view of the Surendra [24] experimental model under compressive concentrated load is displayed in Figure 1.

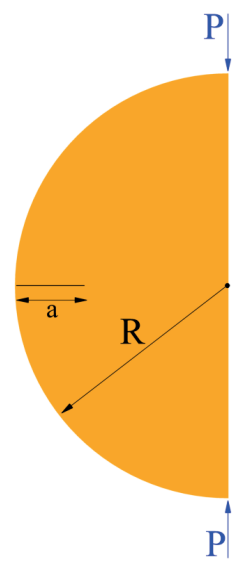

Fig. 1 View of the Surendra [24] experimental model

\section{The Mechanical Behavior of the Semicircular Disc (SD) and the Compressive Load}

In this study, to investigate stress lines in Photo-Elastic materials, a semicircular disc also known as the Brazilian disc with a hypothetical crack with the length $2 \mathrm{a}=2 \mathrm{R}$ was used. Each fringe pattern in Photo-Elastic materials under compressive load, abides by the following equation:

$$
\sigma_{1}-\sigma_{2}=2 \tau_{\max }
$$

In Photo-Elastic materials, considering the fringe order $N$ and the properties of the Photo-Elastic material, stress is defined by the following equation:

$$
\sigma_{1}-\sigma_{2}=\frac{N f_{\sigma}}{t}
$$

In the above equations, $N, t$, and $f_{\sigma}$ are order of the fringe, the thickness of the samples, and the fringe constant of the Photo-Elastic material, respectively. Based on equations (1) and (2), in Zeroth order fringe (ZOF), the shear stress is zero.

$$
\begin{aligned}
& 2 \tau_{\max }=\frac{N f_{\sigma}}{t} \\
& N=0 \Rightarrow\left\{\begin{array}{c}
\tau=0 \\
\sigma_{1}=\sigma_{2}
\end{array}\right.
\end{aligned}
$$

Figure 2.b displays the isochromatic fringe pattern in the semicircular disc. The Zeroth order fringe (ZOF) is between the inner edge and the outer arc and it can be seen that $1 / 3$ of the area close to the outer edge is under tension. Therefore, by creating a small and horizontal crack on the outer arc of the disc, 


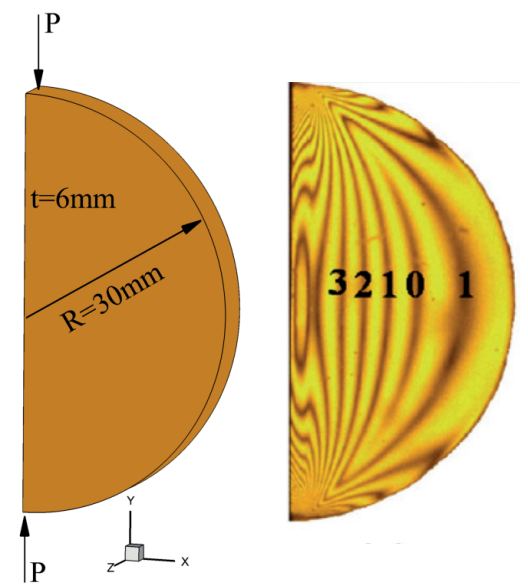

Fig. 2 (a) View of the semicircular disc under compressive load, (b) The isochromatic fringe pattern in the photo-elastic sample under compressive load

it can be ensured that the tip of the crack is under tension and the expansion of the crack is under the first mode. To determine the exact location of the ZOF on the horizontal radius, the normal stress in the $\mathrm{X}$ and $\mathrm{Y}$ directions must be plotted. So, a three-dimensional model of the semicircular disc was created in the ANSYS software and the three-dimensional element Solid186 was used for the analysis. The numerical results of the normal stresses $\sigma_{x}$ and $\sigma_{y}$ along the direction of the horizontal radius are given in Figure 3.

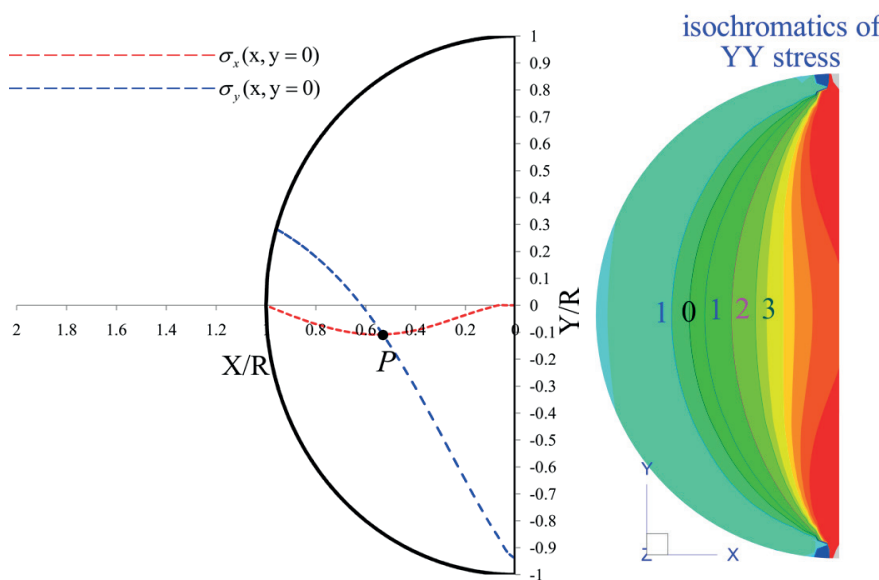

Fig. 3 Uncracked disc under concentrated compressive load: (a) The $\sigma_{x}$ and $\sigma_{y}$ normal stresses along the direction of the horizontal radius, (b) Isochromatic fringe pattern

The $\sigma_{y}$ normal stresses along the length of the horizontal radius of the disc from the vertical edge are compressive and follow a declining trend and reach zero at approximately $18.5 \mathrm{~mm}$ from the vertical edge. From that point toward the end of the disc, the stress is tensile and in an increasing trend. So, considering the pattern of the $\sigma_{x}$ normal stress, Figure 3.a and the Eq.(3) equation, show that the location of the ZOF crosses the point where the two normal stresses intersect $\left(\sigma_{x=} \sigma_{y}\right)$. By considering Figure 3.a, it can be observed that point $P\left(\sigma_{x=} \sigma_{y}\right)$ occurs at $16.9 \mathrm{~mm}$ away from the vertical edge and the Zeroth order fringe goes through this point. In the experimental investigations conducted by Surendra [24], this line crosses a point, $17.1 \mathrm{~mm}$ away from the vertical edge. The difference between the location of point $\mathrm{P}$ in the numerical and experimental models is probably due to the nature of the point load in the numerical model; whereas in the experimental model, the applied pressure to the sample increases, the area over which the load is applied and also the support increase as well and the load exits its concentrated state and follows the Hertzian distribution [25].

To ensure the location of point $P$, the semicircular disc (SD) is considered as a rectangular beam with constant thickness and a varying height of $r_{y}=\sqrt{R^{2}-y^{2}}$ (Figure 4). The load applied to the vertical edge can be replaced by transferring the load and an equivalent moment equal to $\mathrm{Pr} / 2$. The load $\mathrm{P}$ exerts a uniform load $\mathrm{Pt} / \mathrm{r}$ on the location it acts upon. The amount of vertical stress on the symmetry line due to compressive load and moment, can be obtained by (4) equation:

$$
\sigma_{y}=\sigma_{y}^{c}+\sigma_{y}^{b}=-\frac{P}{r t}+\frac{6 P\left(x-\frac{r}{2}\right)}{t r^{2}}=\left(\frac{6\left(x-\frac{r}{2}\right)}{r}-1\right)\left(\frac{P}{t r}\right)
$$

The geometric location of the ZOF can be determined by setting $\sigma_{v}=0$. In this location, no shear stress is present and based on the theoretical solution, the amount of normal stress $\sigma_{x}$ is equal to zero. Therefore, the geometric location of the ZOF can be obtained using equation (5):

$$
\begin{aligned}
& \left(\frac{6\left(x-\frac{r}{2}\right)}{r}-1\right)=0 \\
& \Rightarrow \frac{3}{2} x=r=\sqrt{R^{2}-y^{2}} \Rightarrow\left(\frac{x}{2 R / 3}\right)^{2}+\left(\frac{y}{R}\right)^{2}=1
\end{aligned}
$$

Using the analytic approach, the location of the Zeroth order fringe is obtained as the equation of the ellipse, where the small diameter of the ellipse rests on the $\mathrm{X}$ axis and is given by $2 R / 3=20 \mathrm{~mm}$, which is the analytic location of point $P$. By comparing the analytical and numerical results, it becomes clear that the range for point $P$ for $N=0$ has been correctly calculated.

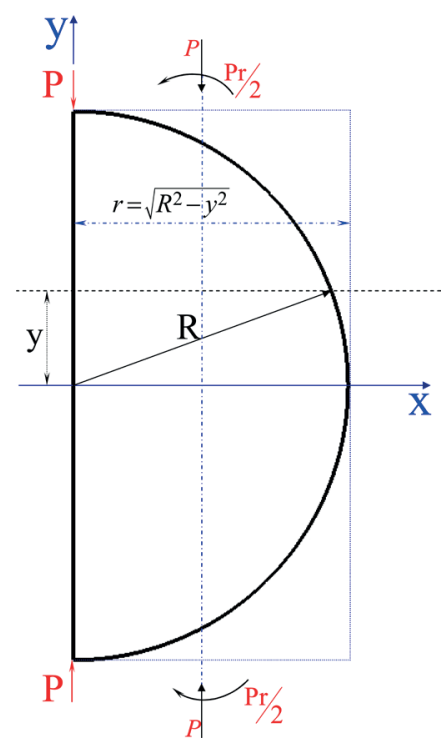

Fig. 4 Analysis of the SD sample using the rectangular beam concept 


\section{Finite element modeling}

To model the edge cracked semicircular disc (ECSD), the three-dimensional Solid186 element was used. This element incorporates 20 nodes with 3 transitional degrees of freedom for each node and is capable of solving singularity and is suitable for modeling the crack tip. Considering the recommendations given by researchers and the user's guide of the software, the radius of the circle made by the elements of the first row on the tip of the crack is at always $L_{e} " a / 8$. In Figure 5, the view of the finite element model, the meshing and the ECSD with a $9 \mathrm{~mm}$ crack are shown.

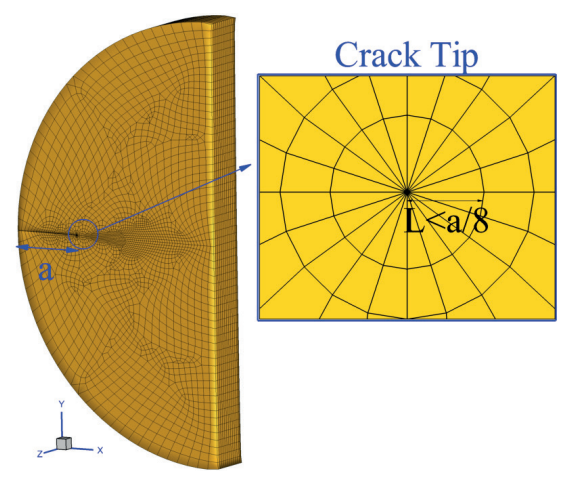

Fig. 5 Finite element model of the cracked disc

To ensure the validity of the results given by the ANSYS software for the $K_{I}$, the results of the experiment conducted by Surendra [24] were employed. Two Photo-elastic Perspex epoxy resin ECSDs with the radius of $30 \mathrm{~mm}$ and a thickness of $6 \mathrm{~mm}$, with cracks of lengths 9 and $11 \mathrm{~mm}$ were tested by Surendra [24] (Figure 6). Considering the pattern of the stress lines in the cracked semicircular disc under a $395 \mathrm{~N}$ uniform compressive load, it is evident that the tip of the crack is under internal tensile force and is opening up. Given the fact that the crack is on the symmetry line of the disc, then, theoretically, the first mode should be the dominant mode. However, a small amount has been recorded for the second mode in the lab (Table 1).

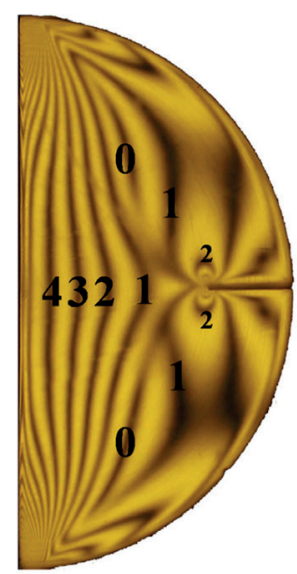

(a)

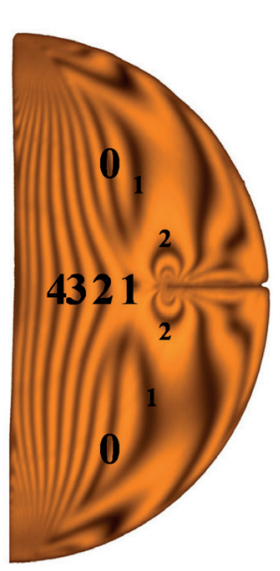

(b)

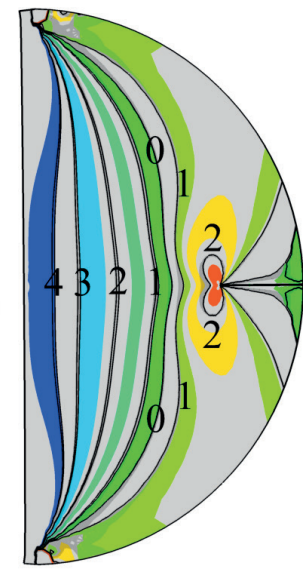

(c)
Fig. 6 Isochromatic fringe pattern for, (a) $a=9 \mathrm{~mm}$, (b) $a=11 \mathrm{~mm}$, (c) $a=9$ mm (numerical)
Correctly applying the load can be really influential in the accuracy of the results. Theoretically, git is assumed that the load is being applied as a point load on the ECSD, but in reality, the location on which the compressive load is being applied and also the support, is compressed and enlarged. Therefore, the load was applied to the sample using the Hertzian distribution so that the load can be more realistic. The compressive load, following a declining trend and with the Hertzian distribution, was applied to the upper nodes of the model. The load applied to each node has been determined through the (6) equations.

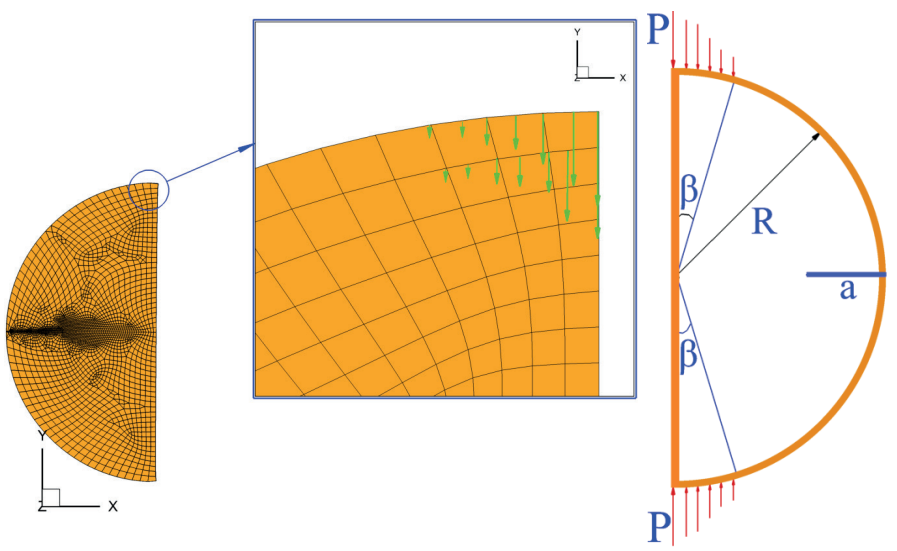

Fig. 7 Load with the hertzian distribution, (a) Nodal force in the numerical model, (b) Overall shape of the hertzian distribution

$$
\begin{aligned}
& V(\theta)=V\left(\frac{\pi}{2}\right) \sqrt{1-\frac{\left(\frac{\pi}{2}-\theta\right)^{2}}{\beta^{2}}} \text { for }\left(\frac{\pi}{2}-\beta\right) \leq \theta \leq \frac{\pi}{2}, \quad V\left(\frac{\pi}{2}\right)=\frac{4 P}{\pi R \beta} \\
& \text { Then } V(\theta)=V\left(\frac{4 P}{\pi R \beta}\right) \sqrt{1-\frac{\left(\frac{\pi}{2}-\theta\right)^{2}}{\beta^{2}}}
\end{aligned}
$$

When compressive load is applied to the samples in the lab, up to an angle of approximately four degrees $\beta=4^{\circ}$, the location on which the load is being applied and the support contribute to the load distribution and thus, in the numerical model with the Hertzian distribution and from the outer edge of the disc, the compressive load is decreasingly applied to the nodes. The compressive load applied to both samples is equal to $395 N$. According to Figure 6 and by comparing the fringe pattern of ECSD with a $=9 \mathrm{~mm}$, a good agreement can be seen between the numerical and the experimental models and the numerical models can almost be trusted. But, to guarantee the results of the numerical model, the $K_{I}$ should be compared in both the numerical and the experimental models.

To calculate the $K_{I}$ in the 3D numerical model, given that stress distribution changes along the thickness of the sample from the outer edge toward the inner area, it is important to select the appropriate section to calculate the stress intensity factor. No stress exists on the boundary on both sides of the outer edge of the crack and a state of planar stress is therefore 
created. However, by moving away from the edge of the disc the tri-axial state of stress gains more significance. So, in Figure 8 , if we move, with the index $S$, toward the coordinate with the index $I$, the behavior of the section shifts from planar stress to planar strain. Given that displacement is greater in the planar stress areas, stress concentration occurs on the inner areas with higher stiffness.

So, the midpoint of the section $t / 2$ was used in the numerical models to calculate the stress intensity factor. Figure 8.b illustrates the $K_{I}$ along the thickness of the disc with a 9 mm crack.

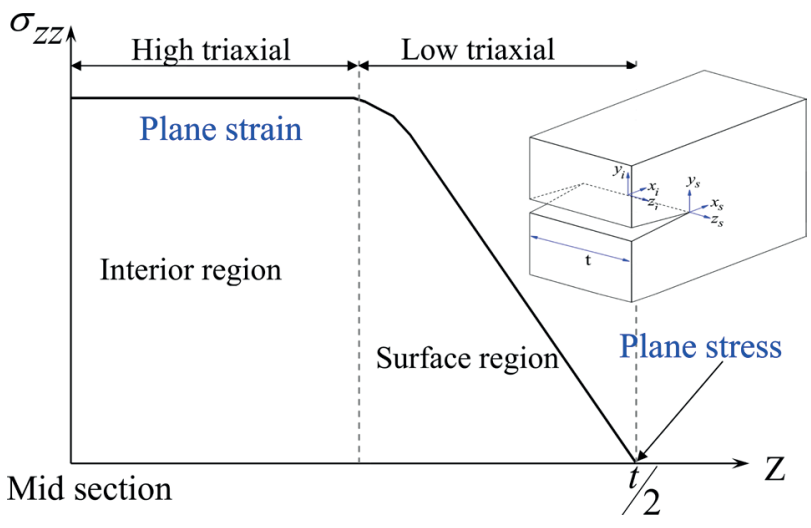

(a)

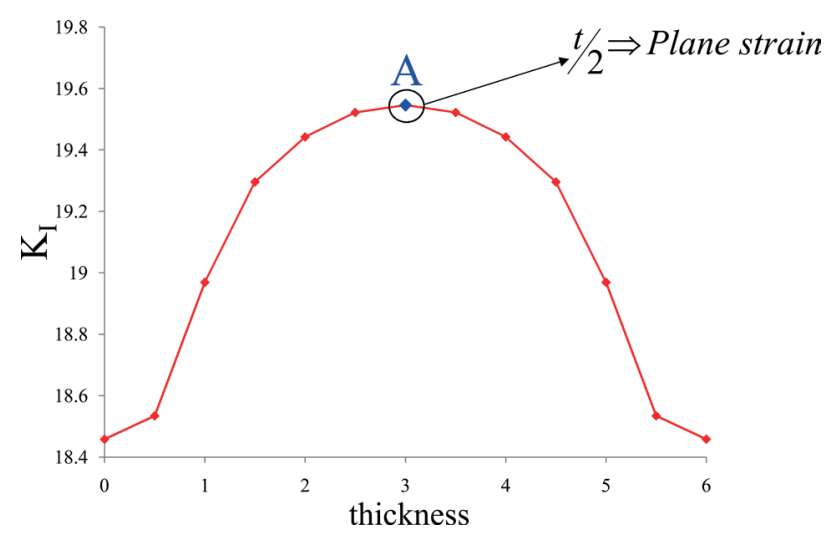

(b)

Fig. 8 (a) Schematic view of stress in thickness of the disc, (b) The value for $K_{I}$ along the thickness of the ECSD with a $=9 \mathrm{~mm}$ crack

In numerical problems, the computational cost and the margin of error are always important factors, therefore a 2D model of the ECSD was also created so that the results could be compared to those of the 3D model and a conclusion can be made, based on computational cost and accuracy required, on which model yields the best results. The values for $K_{I}$ for the numerical Table 1 and experimental models are given. Comparing the relative error of the $K_{I}$ of the two numerical models with the experimental model makes clear that the $3 \mathrm{D}$ model is a lot more accurate because it incorporates almost every aspect of the sample's behavior. But, in the 2D model, in which modeling is in the form of either plane stress or plane strain, a certain stress/strain is neglected. So, the 3D model of the ECSD will be used so that numerical results be closer to reality.
Table 1 Comparison between the stress intensity factors of the 2D, 3D, and experimental model $K(\mathrm{Mpa} \sqrt{\mathrm{mm}})$

\begin{tabular}{lcccc}
\hline Crack length & \multicolumn{2}{c}{ Numerical model } & $\begin{array}{c}\text { Experimental } \\
\text { model }\end{array}$ & $\begin{array}{c}\text { Relative error } \\
\text { percentage }\end{array}$ \\
\hline \multirow{2}{*}{$9 \mathrm{~mm}$} & 2D & 15.846 & & 9.91 \\
& 3D & 17.382 & 17.591 & 1.18 \\
$11 \mathrm{~mm}$ & 2D & 17.894 & & 8.77 \\
& 3D & 19.546 & 19.615 & 0.35 \\
\hline
\end{tabular}

\section{Results}

Considering that obtaining the $K_{I}$ is of high importance, researchers have always tried to devise experiments to obtain the toughness of materials. The tests for obtaining the stress intensity factor often involve subjecting the sample to tensile or bending loads and this requires special lab equipment. Surendra [24], however, presented a simple and quick way for evaluating the toughness of the first mode by subjecting the edge cracked semicircular disc (ECSD) to compressive load. Since placing a semicircular disc under a compressive actuator is statically difficult, therefore by rounding semicircular arch at loading and support locations, the sample under the actuator becomes static and load is applied to the disc uniformly and pressingly. Figure (9) shows a perspective of the proposed model under uniform pressing load.

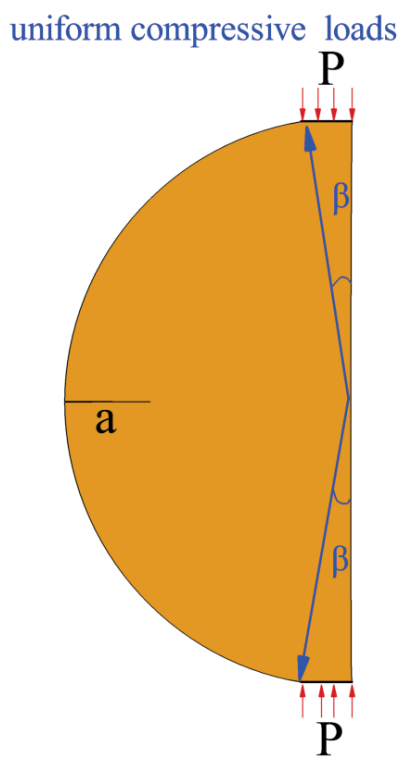

Fig. 9 View of the sample under uniform compressive

\subsection{Assessing the ECSD(UC) with Constant Thickness}

By assuming that angle $\beta$ changes from 0 to 10 degrees with 1 degree increment, the length of the crack (a) changes from 1 $\mathrm{mm}$ to $29 \mathrm{~mm}$ with $1 \mathrm{~mm}$ increment, and a constant thickness of $6 \mathrm{~mm} K_{I}$ is evaluated. 


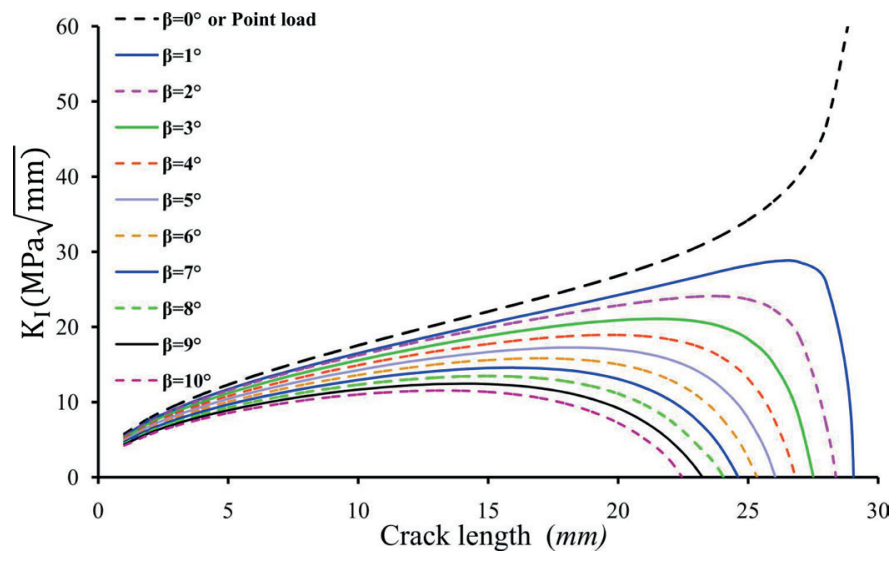

Fig. 10 Values for $K_{I}$ versus crack length

From Figure 10, it can be construed that $K_{I}$ increases as $\beta$ decreases and the reason is that the tensile area on the edges of the semicircular disc was decreased. Also, at a certain angle, as the length of the crack increases, $K_{I}$ first increases and then decreases. The decrease is due to the tip of the crack approaching the compressive zone of the disc which prevents the crack tip from opening. The $\beta=0^{\circ}$ in the graph represents the limit state and since it is the state in which a point load has been applied and the value of $K_{I}$ is purely increasing, no other line in the graph should intersect with the zero limit state line. Also, it is clear from Figure 10 that when the value for $K_{I}$ equals zero at a certain angle, the corresponding crack length $\left(a^{*}\right)$ is the maximum length where the tip of the crack is in tension and the value of is positive. After the tip of the crack is compressed and closed. As it is seen in Figure 10, as $\beta$ angle increases, the crack length for calculating $K_{I}$ in the lab becomes limited and this should be taken into account while the sample is being made in the lab.

The value of $K_{I}$ is negative for lengths larger than $a^{*}$. Although it is physically impossible for $K_{I}$ to be negative, but it would be interesting to theoretically evaluate it. To carry this out, the cracked semicircular disc with a crack length greater than $a^{*}$ was subjected to tensile load with the same magnitude as the compressive load. The values for $K_{I}$ under tensile load were the same as the ones under compressive load with positive sign. In Figure 11, the values of $K_{I}$ under compressive load for a crack length longer than $a^{*}$ are shown.

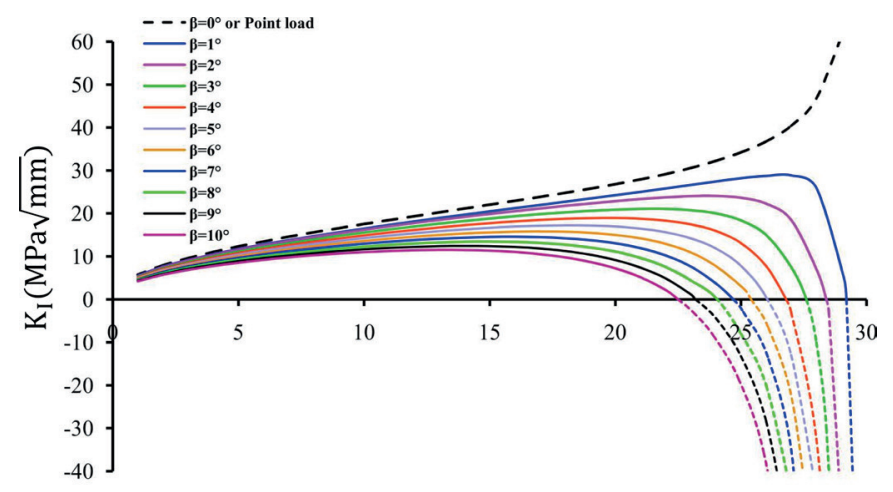

Crack length $(\mathrm{mm})$

Fig. 11 Negative values of $K_{I}$ for a length greater than $a^{*}$
To obtain the constant shape factor of the ECSD(UC), the $K_{I}$ values and the length of the crack (a) should be made dimensionless. In Figure 12, the normalized stress intensity factor $K_{I} / P / R t^{\sqrt{\neq a}}$ against relative crack length is drawn.

As it can be seen from Figure 12, the pattern of the diagram is similar to that of Figure. 10 with the difference that the horizontal region of the graph has increased and considering the equation $K_{I} / P / R t \sqrt{\neq a}=F$ the shape factor values approach a constant number.

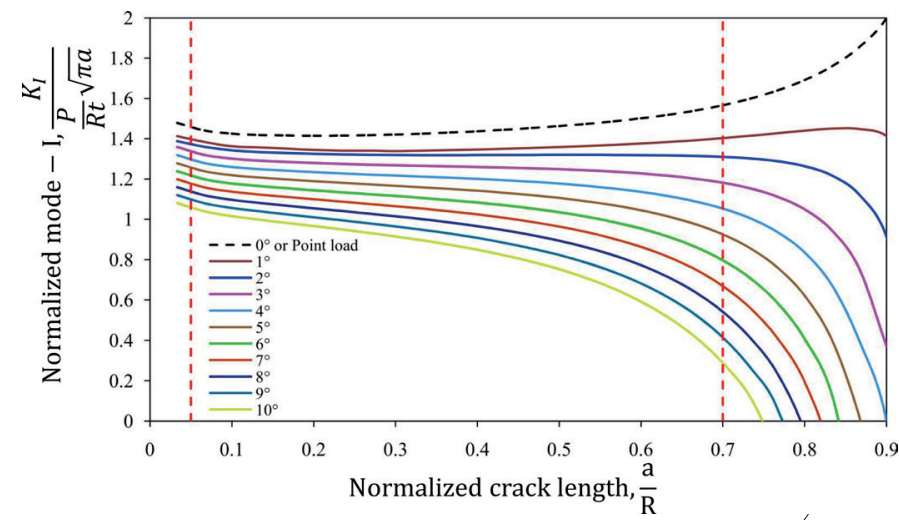

Fig. 12 Normalized $K_{I}$ values against relative crack length $a / R$

As it is evident from Figure 12, within the range $0.067 \leq a / R$ $\leq 0.6$, almost all lines in the normalized $K_{I}$ - relative crack length $(a / R)$ diagram are more horizontal and therefore this zone was chosen to select the constant shape factor $(F)$. Then, by calculating the standard deviation and the $C_{v}$ in the shape factor $(F)$ for all the angles in this range, it was determined that the loading angle $\beta=2^{\circ}$ in the range $0.067 \leq a / R \leq 0.6$ has the lowest coefficient of variation in the shape factor which means that in this loading angle, the diagram is more horizontal compared to the other diagrams and has a smaller error. Also, the mean average of the shape factors is obtained with a good approximation.

Table 2 Mean average, standard deviation and coefficient of variation values of the shape factor

\begin{tabular}{llcc}
\hline$\beta$ in degrees & Mean & Standard deviation & $\mathrm{CV} * 100 \%$ \\
\hline $0^{\circ}$ & 1.441 & 0.03 & 1.85 \\
$1^{\circ}$ & 1.353 & 0.01 & 1.02 \\
$2^{\circ}$ & 1.325 & 0.01 & 0.84 \\
$3^{\circ}$ & 1.267 & 0.02 & 1.86 \\
$4^{\circ}$ & 1.210 & 0.04 & 3.17 \\
$5^{\circ}$ & 1.152 & 0.05 & 4.65 \\
$6^{\circ}$ & 1.095 & 0.07 & 6.30 \\
$7^{\circ}$ & 1.038 & 0.08 & 8.13 \\
$8^{\circ}$ & 0.981 & 0.10 & 10.17 \\
$9^{\circ}$ & 0.924 & 0.12 & 12.48 \\
$10^{\circ}$ & 0.867 & 0.13 & 15.07 \\
\hline
\end{tabular}


The stress intensity factor, from equation (7), is obtained as follows:

$$
K_{I}=F \sigma \sqrt{\pi a}
$$

In this equation, $F$ is the shape factor of the disc and is dependent on the geometry of the sample. From Table 2, this value for the edge crack semicircular disc under uniform compressive load (ECSD(UC)) at an angle equal to $\beta=2^{\circ}$ was determined equal to 1.325 . Also, the stress intensity factor of the first mode for the cracked semicircular disc with a thickness of $6 \mathrm{~mm}$ is obtained through the equation below:

$$
K_{I}^{E C S D}=1.325 \frac{P}{R t} \sqrt{\pi a}
$$

\subsection{The Simultaneous Effect of Thickness and Crack Length on the Shape Factor of the Cracked Semicircular Disc under Uniform Compressive Load ECSD(UC)}

Since in laboratory samples are made and studied with different dimesnions, investigating samples with different crack length and thicknes is of great significance. Since the functional coefficent comes from the shape and geometry of the sample, then samples were studied with different lenght and crack thickness. According to the 5.1 results, sample shape factor at the angle $\beta=2^{\circ}$ had the lowest variation coefficient percentage, therefore by keeping the angle $\beta$ constant, a relationship based on thickness and crack length was proposed to calculate the shape factor of the ECSD(UC). So, ECSD(UC) with a thickness varying from 1 to $30 \mathrm{~mm}$ with $1 \mathrm{~mm}$ increment and a crack length varying from 1 to $29 \mathrm{~mm}$ with $1 \mathrm{~mm}$ increment was analyzed while under uniform compressive load. Then, according to the acquired results and based on Figure 13.a, the value of the normalized stress intensity factor has the lowest $C_{v}$ within the relative crack length range of $0.067 \leq a / R \leq 0.8$. Also, the normalized stress intensity factor has the lowest $C_{v}$ within the relative thickness range of $0.067 \leq a / R \leq 1$. Therefore, in order to take the effects of these two factors into account, the two previously mentioned ranges were used in the given relationship.

To observe the effect of both factors on the shape factor, in $3 \mathrm{D}$ space, the normalized stress intensity factor has been drawn against relative crack length $(a / R)$ and relative thickness $(t / R)$ in Figure 14. According to Figure 14, it is clear that for a certain ratio of relative thickness, the normalized $K_{I}$ has a declining trend which is due to the increase of the length of the crack and the tip of the crack approaching the ZOF. Further, for a certain relative crack, the value of the normalized $K_{I}$ follows a lessening trend and as the relative thickness increases, it approaches a constant value.

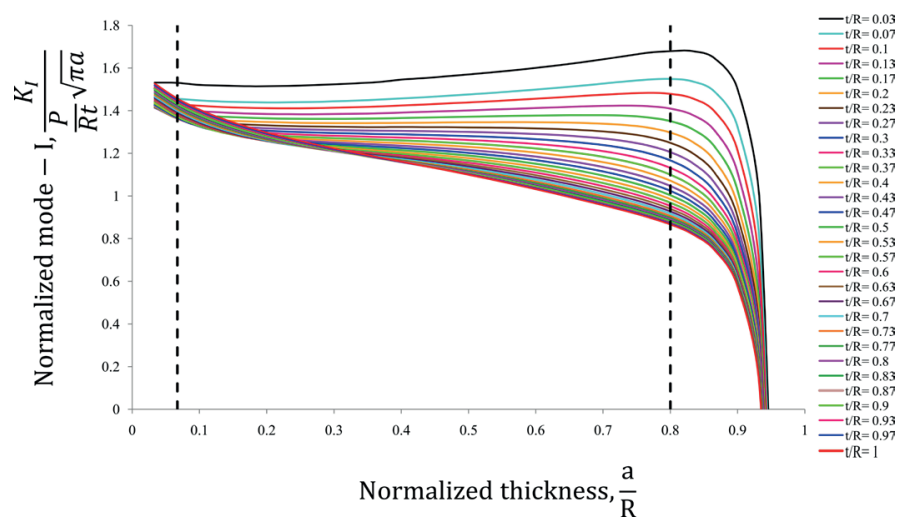

(a)

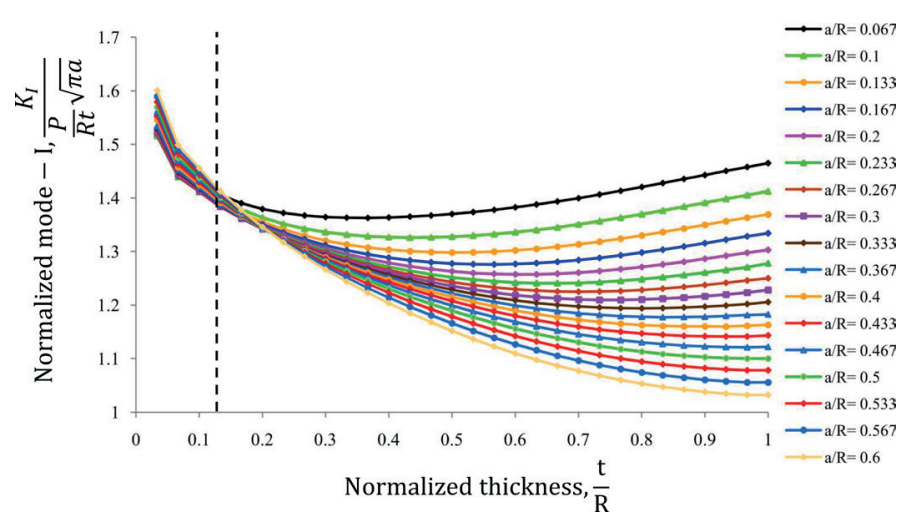

(b)

Fig. $13 K_{I}$ against: (a) Relative crack length, (b) Relative thickness

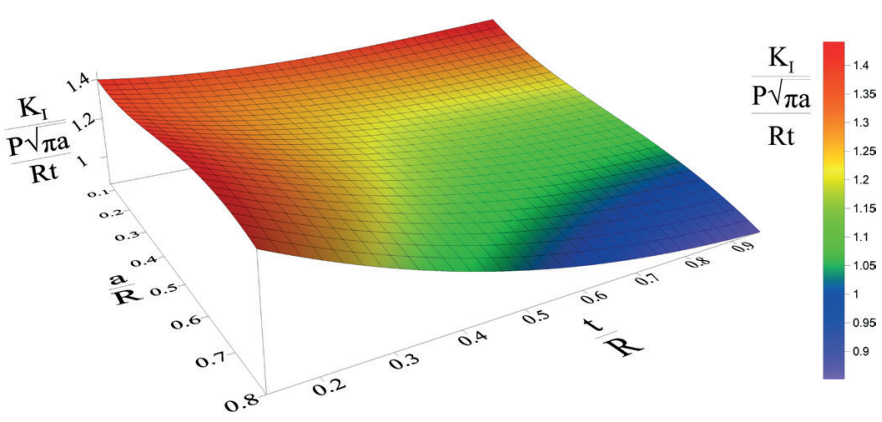

Fig. 14 The values of $K_{I}$ against relative crack length $(a / R)$ and relative thickness $\left(t / T_{R}\right)$ in $3 \mathrm{D}$ space

To achieve the equation of Figure 14, the polynomial regression was employed. The relative crack length is represented by $\mathrm{X}$ and the relative thickness is represented by Y. By carrying out 4 regressions Simple planar surface, Bi-linear saddle, Quadratic surface, and Cubic surface and calculating the value of RMSE of the four regressions with the results of the finite element method, it was observed that amongst the four regressions, the Cubic surface regression has the smallest value of RMSE among the four regressions. Table 3 contains the maximum relative error values, RMSE and the coefficients of each of the proposed regressions. 
Table 3 Maximum relative error values and the coefficients of each regression

\begin{tabular}{|c|c|c|c|c|}
\hline 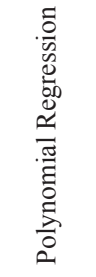 & $\begin{array}{c}\mathrm{F}(X, Y)= \\
\mathrm{A}_{00}+\mathrm{A}_{01} y \\
+\mathrm{A}_{02} y^{2}+\mathrm{A}_{03} y^{3} \\
+\mathrm{A}_{10} x+\mathrm{A}_{11} x y \\
+\mathrm{A}_{12} x y^{2}+\mathrm{A}_{20} x^{2} \\
+\mathrm{A}_{21} x^{2} y+\mathrm{A}_{30} x^{3}\end{array}$ & $\begin{array}{c}\mathrm{F}(X, Y)= \\
\mathrm{A}_{00}+\mathrm{A}_{01} y+ \\
\mathrm{A}_{02} y^{2}+\mathrm{A}_{10} x \\
+\mathrm{A}_{11} x y+\mathrm{A}_{20} x^{2}\end{array}$ & $\begin{array}{c}\mathrm{F}(X, Y)= \\
\mathrm{A}_{00}+\mathrm{A}_{01} y \\
+\mathrm{A}_{10} x+\mathrm{A}_{11} x y\end{array}$ & $\begin{array}{c}\mathrm{F}(X, Y)= \\
\mathrm{A}_{00}+\mathrm{A}_{01} y \\
+\mathrm{A}_{10} x\end{array}$ \\
\hline $\mathrm{A} 00$ & 1.478 & 1.442 & 1.325 & 1.544 \\
\hline A01 & -0.428 & -0.460 & 0.111 & -0.286 \\
\hline A10 & -0.439 & 0.150 & 0.102 & -0.401 \\
\hline A11 & -1.709 & -0.916 & -0.915 & \\
\hline A02 & 0.818 & 0.519 & & \\
\hline A20 & 2.082 & -0.054 & & \\
\hline A03 & -0.323 & & & \\
\hline A12 & 0.538 & & & \\
\hline A21 & 0.232 & & & \\
\hline A30 & -1.741 & & & \\
\hline RMSE & 0.006776 & 0.018054 & 0.034195 & 0.061084 \\
\hline $\begin{array}{c}\% \text { Max } \\
\text { Error }\end{array}$ & 2.81 & 5.87 & 9.22 & 15.93 \\
\hline
\end{tabular}

Considering the formula $K_{I} / \sigma \sqrt{\pi a}=F$, the value of $F$ depends on the geometry and the length of the crack. Therefore, considering the relative error percentage in Table 3, the equation of the Cubic surface regression is recommended and from Eq. (9), the value of the shape factor of the ECSD(UC) within the selected range can be obtained.

$$
\begin{aligned}
& \mathrm{F}\left(\frac{a}{R}, \frac{t}{R}\right)=1.478-0.428\left(\frac{t}{R}\right)+0.818\left(\frac{t}{R}\right)^{2}-0.323\left(\frac{t}{R}\right)^{3} \\
& -0.439\left(\frac{a}{R}\right)+2.082\left(\frac{a}{R}\right)^{2}-1.741\left(\frac{a}{R}\right)^{3} \\
& +0.232\left(\frac{a}{R}\right)^{2}\left(\frac{t}{R}\right)-1.709\left(\frac{a}{R}\right)\left(\frac{t}{R}\right)+0.538\left(\frac{a}{R}\right)\left(\frac{t}{R}\right)^{2} \\
& ,\left\{\begin{array}{l}
0.067 \leq \frac{a}{R} \leq 0.8 \\
0.13 \leq \frac{t}{R} \leq 1
\end{array}\right.
\end{aligned}
$$

By comparing the values of shape factor $(F)$ resulted from mathematical relations and finite element method, the complete agreement of cubic surface relation is revealed.

Equation (9) can be used for a wide range of crack lengths and thicknesses and provides an accurate approximation of the shape factor $(F)$. In Figure. 16, the relative error percentage of equation (9) is plotted against numerical results of finite element. According to Figure. 16, a wide spectrum of relative errors is beneath 1 percent which shows a good agreement between mathematical relation and values of finite element. By using relation (9) and figure (16) dimensions of laboratory samples can be made in a way that shape factor would have the lowest error percentage for semi-circular disc under uniform compressive load.

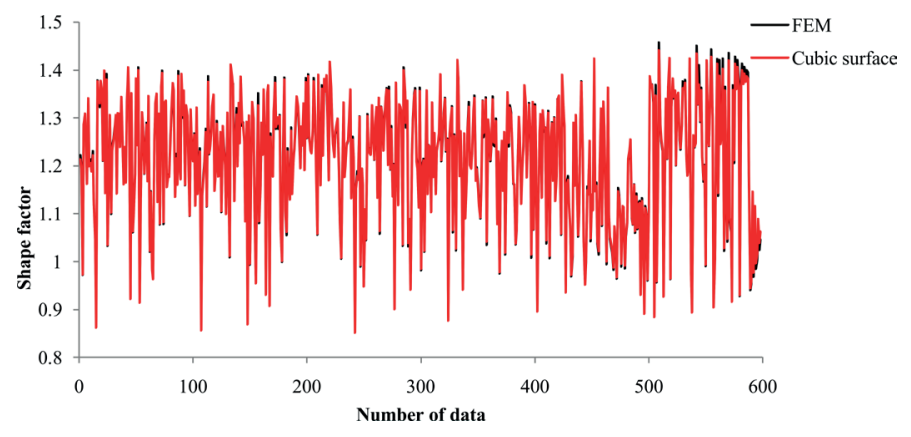

(a)

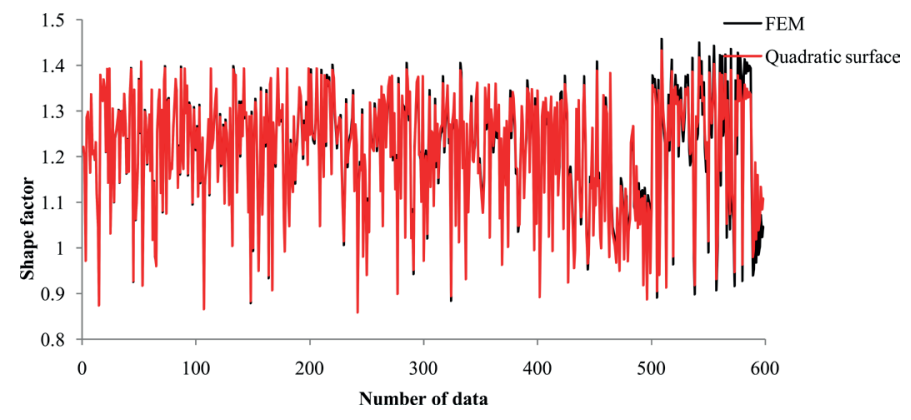

(b)

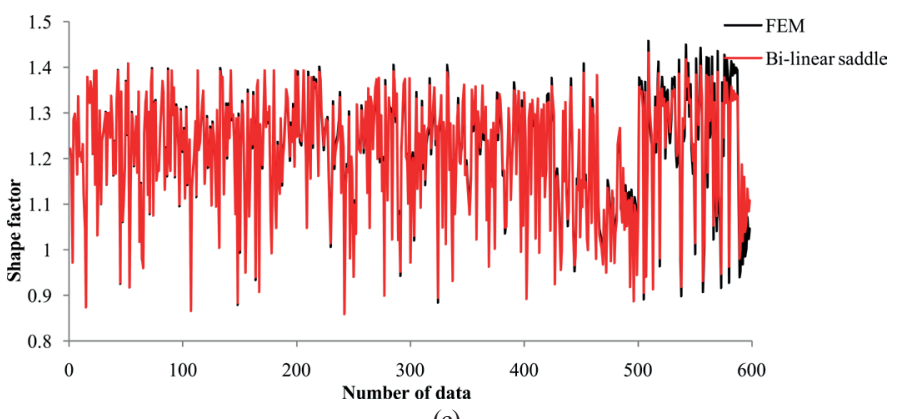

(c)

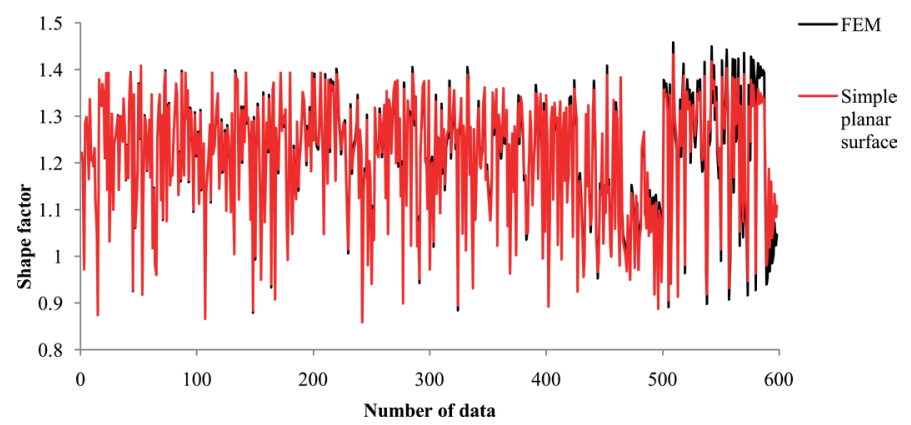

(d)

Fig. 15 Comparison of shape factor values of finite element model and mathematical regression.(a) Quadratic surface. (b) Quadratic surface. (c) Bi-linear saddle. (d) Simple planar surface

\section{Conclusions}

Using the edge cracked semicircular disc(ECSD) under compressive load is a good method to measure the toughness of brittle materials. This method calculates, with good accuracy, the toughness of the first mode of brittle materials under uniform compressive load. Given that it might be difficult in the lab to apply compressive load to a sample that is not rounded off, rounding off the support area and the location where the load is being applied can solve this problem. In this study, a 


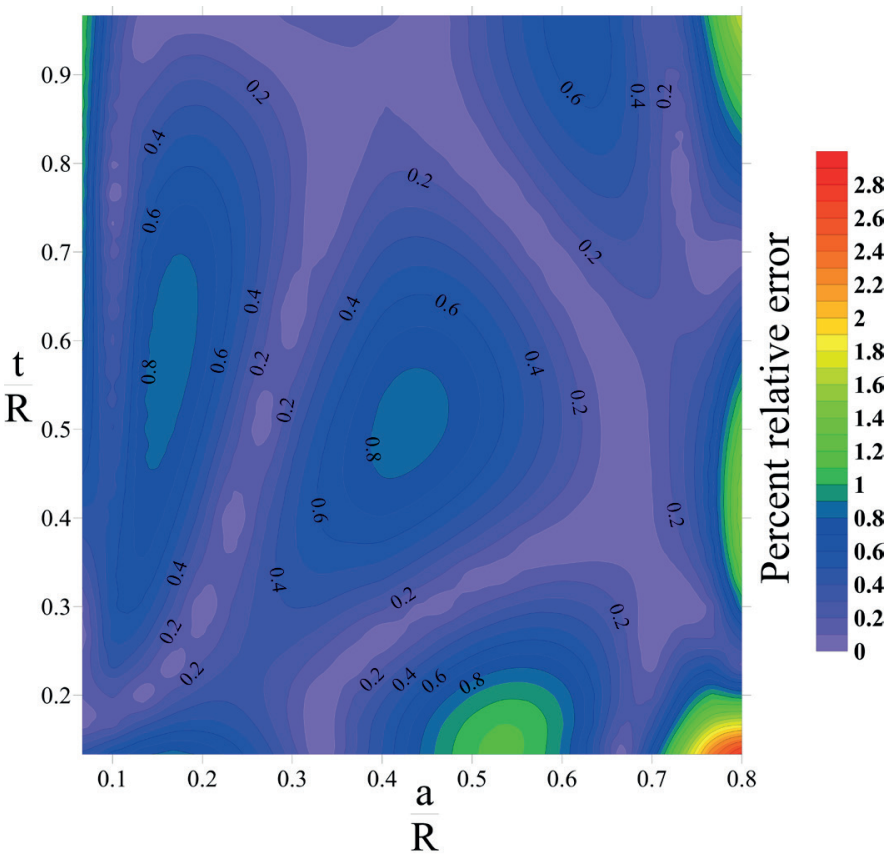

Fig. 16 Relative error percentage of the proposed relationship and the numerical model

wide range of rounded-off area and angle $\beta$, as well as different crack lengths were investigated. The results showed that the $\operatorname{ECSD}(\mathrm{UC})$ with a thickness of $6 \mathrm{~mm}$ under uniform compressive load and a round off length corresponding to an angle of $\beta=2^{\circ}$ has a constant shape factor of $F=1.325$. Considering the variation coefficient percentage, the shape factor of the $\operatorname{ECSD}$ (UC) at the angle $\beta=2^{\circ}$ was the lowest, by keeping $\beta$ constant, the effects of relative thickness and relative crack length on the shape factor was assessed and by taking into account the two variables, a relationship was proposed. Given the good agreement between the proposed equation and the numerical results, by considering different thicknesses and crack lengths, the equation can be used to obtain the shape factor of the cracked semicircular disc under uniform compressive load.

\section{References}

[1] Westergaard, H. M.W. "Bearing Pressures and Cracks". Journal of Applied Mechan-ics, 6, A49-A53. 1939.

[2] Wang, Q.-Z., Xing, L. "Determination of fracture toughness K IC by using the flattened Brazilian disk specimen for rocks". Engineering fracture mechanics, 64(2), pp. 193-201. 1999. https://doi.org/10.1016/S00137944(99)00065-X

[3] Ayatollahi, M., Aliha, M. R. M. "On determination of mode II fracture toughness using semi-circular bend specimen". International Journal of Solids and Structures, 43(17), pp. 5217-5227. 2006. https://doi. org/10.1016/j.ijsolstr.2005.07.049

[4] Lim, I., et al. "Fracture testing of a soft rock with semi-circular specimens under three-point bending. Part 2 -mixed-mode". International journal of rock mechanics and mining sciences \& geomechanics abstracts, 31(3), pp. 199-212. 1994. https://doi.org/10.1016/0148-9062(94)90464-2

[5] Surendra, K.V.N., Simha, K.R.Y. "Design and analysis of novel compression fracture specimen with constant form factor: Edge cracked semicircular disk (ECSD)". Engineering Fracture Mechanics, 102, pp. 235-248. 2013. https://doi.org/10.1016/j.engfracmech.2013.02.014
[6] Atkinson, C., Smelser, R., Sanchez, J. "Combined mode fracture via the cracked Brazilian disk test". International Journal of Fracture, 18(4), pp. 279-291. 1982. https://doi.org/10.1007/BF00015688

[7] Akbardoost, J., Ghadirian, H.R., Sangsefidi, M. "Calculation of the crack tip parameters in the holed-cracked flattened Brazilian disk (HCFBD) specimens under wide range of mixed mode I/II loading". Fatigue \& Fracture of Engineering Materials \& Structures, 40(9), pp. 1416-1427. 2017. https://doi.org/10.1111/ffe.12585

[8] Aliha, M.R.M., Ayatollahi, M. R. "Rock fracture toughness study using cracked chevron notched Brazilian disc specimen under pure modes I and II loading - A statistical approach". Theoretical and Applied Fracture Mechanics, 69, pp. 17-25. 2014. https://doi.org/10.1016/j. tafmec.2013.11.008

[9] Ayatollahi, M. R., Zakeri, M. "An improved definition for mode I and mode II crack problems". Engineering Fracture Mechanics, 175, pp. 235-246. 2017. https://doi.org/10.1016/j.engfracmech.2017.01.027

[10] Wei, M. D., Dai, F., Xu, N. W., Zhao, T., Xia, K. W. "Experimental and numerical study on the fracture process zone and fracture toughness determination for ISRM-suggested semi-circular bend rock specimen". Engineering Fracture Mechanics, 154, pp. 43-56. 2016. https://doi. org/10.1016/j.engfracmech.2016.01.002

[11] Gludovatz, B., Granata, D., Thurston, K. V. S., Loffler, J., Ritchie, R. O. "On the understanding of the effects of sample size on the variability in fracture toughness of bulk metallic glasses". Acta Materialia, 126, pp. 494-506. 2017. https://doi.org/10.1016/j.actamat.2016.12.054

[12] Noury, P., Eriksson, K. "Determination of stress intensity factors for cracked bridge roller bearings using finite element analyses". Engineering Fracture Mechanics, 169, pp. 67-73. 2017. https://oi.org/10.1016/j. engfracmech.2016.10.018

[13] Zhu, X.-K., Joyce, J. A. "Review of fracture toughness (G, K, J, CTOD, CTOA) testing and standardization". Engineering Fracture Mechanics, 85, pp. 1-46. 2012. https://doi.org/10.1016/j.engfracmech.2012.02.001

[14] Dong, S., "Theoretical analysis of the effects of relative crack length and loading angle on the experimental results for cracked Brazilian disk testing". Engineering Fracture Mechanics, 75(8), pp. 2575-2581. 2008. https://doi.org/10.1016/j.engfracmech.2007.09.008

[15] Dong, S., Wang, Y., Xia, Y. "A finite element analysis for using Brazilian disk in split Hopkinson pressure bar to investigate dynamic fracture behavior of brittle polymer materials". Polymer Testing, 25(7), pp. 943-952. 2006. https://doi.org/10.1016/j.polymertesting.2006.06.003

[16] Maigre, H., Rittel, D. "Mixed-mode quantification for dynamic fracture initiation: application to the compact compression specimen". International Journal of Solids and Structures, 30(23), pp. 3233-3244. 1993. https://doi.org/10.1016/0020-7683(93)90111-J

[17] Bui, H.D., Maigre, H., Rittel, D. "A new approach to the experimental determination of the dynamic stress intensity factor". International Journal of Solids and Structures, 23(23), pp. 2881-2895. 1992. https:// doi.org/10.1016/0020-7683(92)90146-K

[18] Albinmousa, J., Merah, N., Khan, S. M. A. "A model for calculating geometry factors for a mixed-mode I-II single edge notched tension specimen". Engineering Fracture Mechanics, 78(18), pp. 3300-3307. 2011. https://doi.org/10.1016/j.engfracmech.2011.09.005

[19] Keles, C., Tutluoglu, L. "Investigation of proper specimen geometry for mode I fracture toughness testing with flattened Brazilian disc method". International Journal of Fracture, 169(1), pp. 61-75. 2011. https://doi. org/10.1007/s10704-011-9584-Z

[20] Zerbst, U., Madia, M., Beier, H. T. "A model for fracture mechanics based prediction of the fatigue strength: Further validation and limitations". Engineering Fracture Mechanics, 130, pp. 65-74. 2014. https:// doi.org/10.1016/j.engfracmech.2013.12.005 
[21] Zerbst, U., Madia, M., Vomwald, M., Beier, H. Th. "Fatigue strength and fracture mechanics - A general perspective". Engineering Fracture Mechanics. In Press. https://doi.org/10.1016/j.engfracmech.2017.04.030

[22] Seif, A.E., Kabir, M. Z. "Experimental study on the fracture capacity and fatigue life reduction of the tensioned cracked plate due to the local buckling". Engineering Fracture Mechanics, 175, pp. 168-183. 2017. https://doi.org/10.1016/j.engfracmech.2017.01.023

[23] Simha, K. "Fracture mechanics for modern engineering design". Universities press. 2001.
[24] Surendra, K. "Theoretical and experimental analysis of cracked disks". Master of Engng dissertation. IISc Mechanical Engng, 2010. https://doi. org/10.1111/j.1460-2695.1994.tb00253.x

[25] Chaudhary, A. B., Bathe, K.-J. "A solution method for static and dynamic analysis of three-dimensional contact problems with friction". Computers \& Structures, 24(6), pp. 855-873. 1986. https://doi.org/10.1016/00457949(86)90294-4 